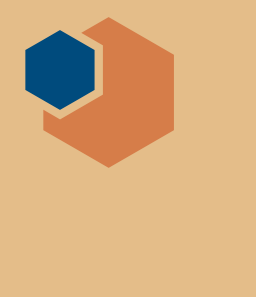

\section{US Congress proposes alternative to COMPETES Act}

T he protocols for federal research funding in the United States are currently a topic of significant debate in the U.S. Congress. In November, Republicans in the House of Representatives released a discussion draft of the FIRST Act, which stands for Frontiers in Innovation, Research, Science, and Technologytheir proposed alternative to the expired COMPETES (America Creating Opportunities to Meaningfully Promote Excellence in Technology, Education, and Science) Act. The FIRST Act addresses federal research and education priorities of the National Science Foundation (NSF), the National Institute of Standards and Technology (NIST), the White House Office of Science and Technology Policy (OSTP), and interagency science, technology, engineering, and mathematics (STEM) programs - all of which provide significant support for materials research.

COMPETES was first passed in 2007 and reauthorized in 2010 with broad bipartisan support. The law authorized increased government investment in basic sciences with a goal of doubling the basic sciences research budget over the course of a decade. While appropriations for COMPETES never met authorized amounts, the law nevertheless established the Advanced Research Projects Agency-Energy (ARPA-E) to fund high-risk/ high-reward science, created programs to develop STEM education, and boosted the budgets of the institutions conducting basic sciences research - namely the NSF, the Department of Energy (DOE) Office of Science, and NIST.

Although COMPETES is broadly credited with keeping U.S. basic sciences research globally competitive, it was allowed to expire in September 2013 amid government turmoil just before the October 2013 U.S. government shutdown. The expiration of the law left the door open for proposed alternatives and in a November 13, 2013 hearing, the Research Subcommittee of the House Science Committee examined the FIRST Act discussion draft as an alternative to COMPETES.

The hearing largely focused on the "national interest" requirement for NSF grants outlined in the discussion draft of the FIRST Act. Prior to awarding research funds, the NSF would be required to publish a written justification of how each grant is in the national interest, is worthy of federal funding, and achieves one of the six strategic goals outlined in the FIRST Act. These goals include increased economic competitiveness, advancement of health and welfare, development of a STEM workforce and increased public scientific literacy, increased partnerships between academia and industry, promotion of the progress of science, and support for national defense.

Research and Technology Subcommittee Chair Larry Bucshon (R-Ind.) supported the changes to the NSF review process in his opening statement saying that the proposed legislation "improves transparency of taxpayer-funded research by making more information available to the public about awarded grants and how they promote the national interest." But while committee members and witnesses alike agreed that transparency in government-funded research is important, Subcommittee Ranking Member Daniel Lipinski (D-Ill.) expressed concern that the criteria used in the bill are vague and said, "at best this language may add a good deal of uncertainty as to how research grants would be awarded, at worst I fear it could fundamentally alter how merit review is done at an agency that is viewed as a gold standard by the rest of the world."

Richard Buckius, Vice President for Research at Purdue University and a witness at the hearing, expressed concern with the proposed changes to the NSF review process saying, "the prior publication of awards and associated information will severely compromise the process and add tremendous administrative burden." Buckius said the current NSF peer-review process is "a valuable service provided to the nation" and added that he believes "it needs to be preserved."

The discussion draft of the FIRST Act also addresses misrepresentation of results, setting a requirement for NSFfunded researchers to certify the veracity of their published research results and banning any primary investigator found guilty of misrepresentation from receiving federal funding for 10 years. While it is extremely important to both the advancement and reputation of science to ensure that results are reported with

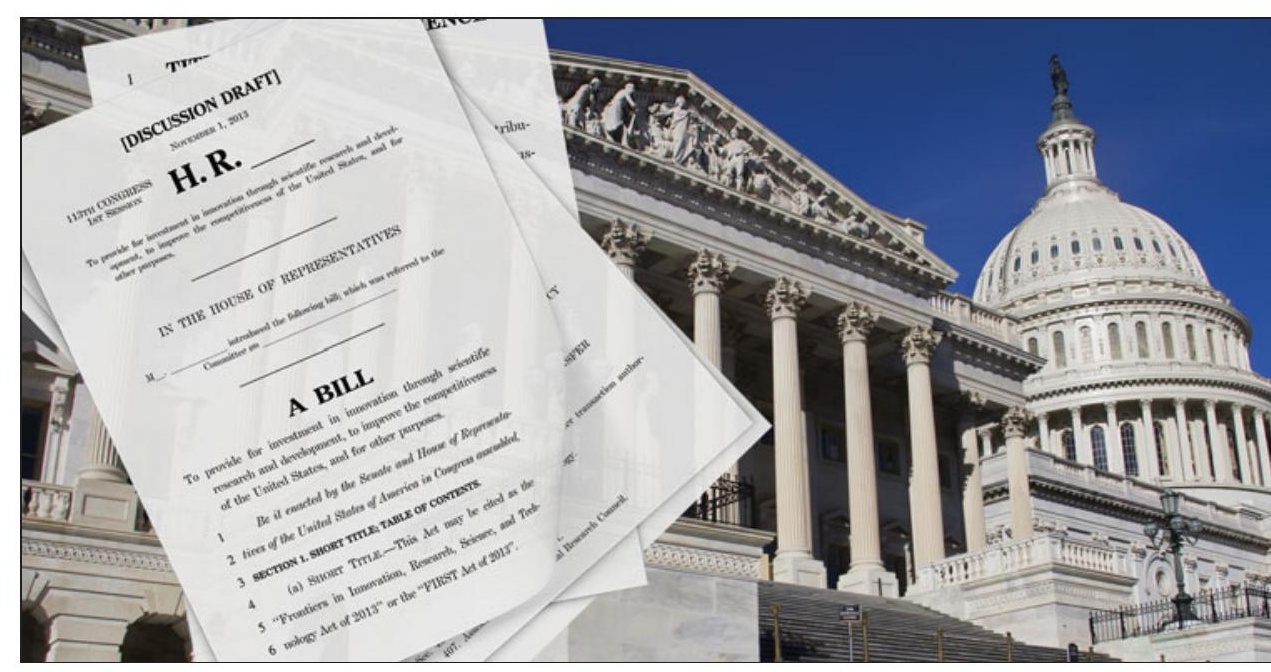


integrity, Eddie Bernice Johnson (D-Texas), Ranking Member of the House Science Committee said, "it troubles me that this draft seems to be dominated in both tone and volume by everything that some of my colleagues believe NSF and scientists are doing wrong, and contains very little in the way of a vision for the future."

In addition to concerns over the proposed changes to NSF, committee members and witnesses expressed concern that key points were not included in the FIRST Act discussion draft. Ranking Member Lipinski noted the lack of authorization funding levels and pointed out that although they cannot set the budget, as an authorizing committee they should be "leading the discussion about authorization levels that reflect a smart and balanced approach to making sure we remain strong and competitive in science, technology, and innovation."

Hearing witness James Brown, the executive director of the STEM Education Coalition, said that the mission of the STEM Education Advisory panel outlined in the FIRST Act discussion draft lacked "a specific charge to address diversity, inclusion, and equity issues." And the provisions around open public access - namely that access to federally funded articles may be delayed by up to 24 months after publication-were also addressed by Buckius who said that there are good arguments on both sides of the time delay but that "it is important to proceed with the implementation as soon as possible and with a shorter publication delay."

Despite the concerns raised with the FIRST Act, Chair Bucshon reminded committee members and witnesses that it is a discussion draft and welcomed input for future revisions. The FIRST Act is also not the only discussion draft under consideration to replace the expired COMPETES Act. House Democrats have released a discussion draft of COMPETES and House Republicans have released a discussion draft of the Enabling Innovation for Science, Technology, and Energy in America (EINSTEIN) Act, which is complementary to the FIRST Act and addresses only the DOE's Office of Science.

In addition to the action in the House, the Senate Commerce, Science, and Transportation Committee also held a hearing to examine federal science funding and its impact on the US economy. During this November 6, 2013 hearing, Senator Lamar Alexander (RTenn.), who championed the original COMPETES legislation, served as a witness and called on his senate colleagues to "finish the job" of doubling the US basic sciences research budget.

It is heartening to see Congress discussing these important bills, and there will likely be future revisions and hearings on the topic. Now is the time for researchers to weigh in and help shape the future of science funding in the United States.

Jennifer A. Nekuda Malik

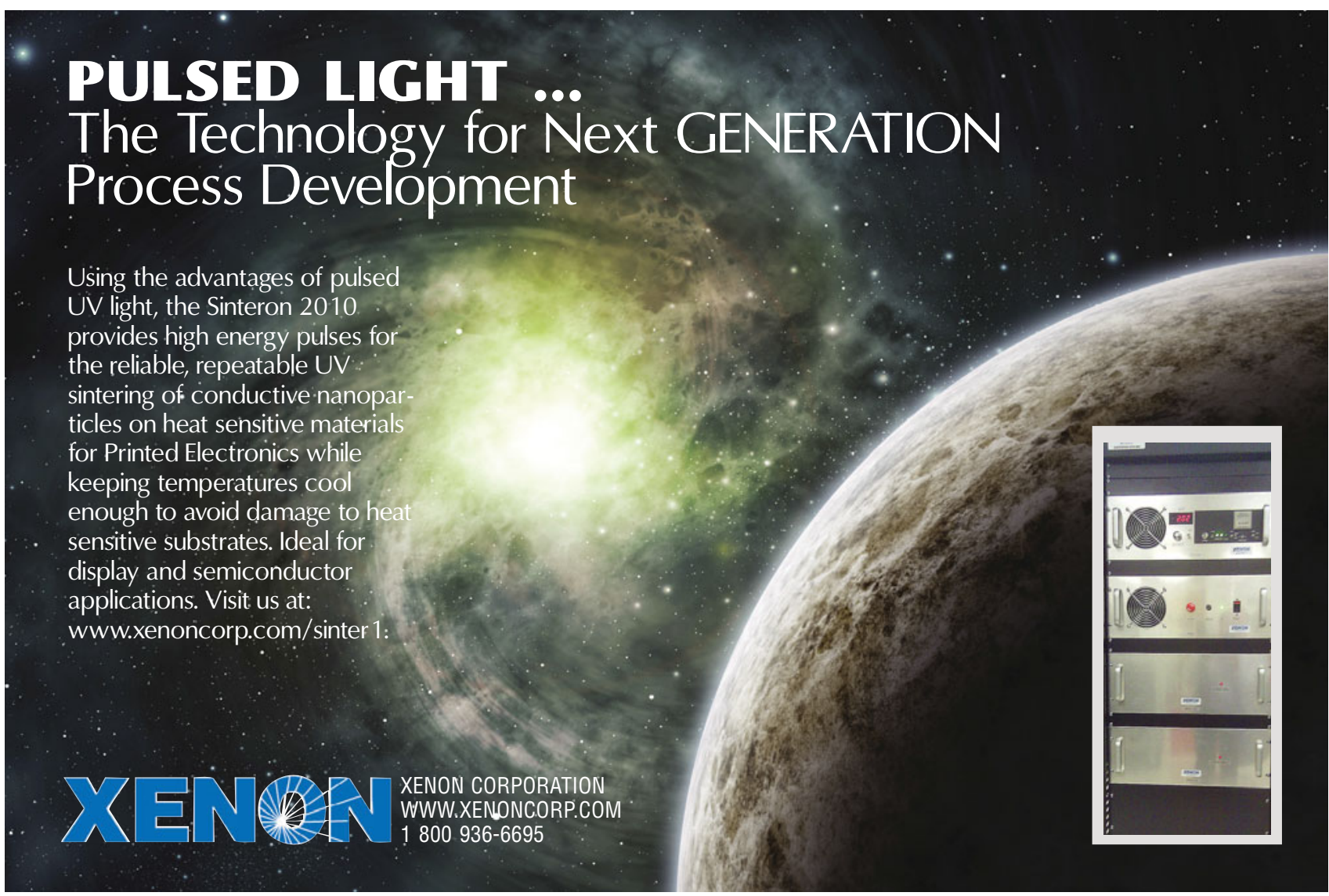

